\title{
A Herbal Mixture from Propolis, Pomegranate, and Grape Pomace Endowed with Anti-Inflammatory Activity in an In Vivo Rheumatoid Arthritis Model
}

\author{
Valentina Parisi ${ }^{1,2}$, Antonio Vassallo ${ }^{3}\left(\mathbb{D}\right.$, Claudio Pisano ${ }^{4, *}$, Giacomo Signorino ${ }^{4}(\mathbb{D}$, \\ Francesco Cardile ${ }^{4}$, Milena Sorrentino ${ }^{4}$, Fabiana Colelli ${ }^{4}$, Alessandra Fucci ${ }^{4}$, \\ Egildo Luca $D^{\prime}$ Andrea ${ }^{4}$, Nunziatina De Tommasi ${ }^{1, *(\mathbb{D}}$, Alessandra Braca ${ }^{5,6} \mathbb{C}^{\circ}$ and \\ Marinella De Leo ${ }^{5,6}$ (D) \\ 1 Dipartimento di Farmacia, Università degli Studi di Salerno, 84084 Fisciano (SA), Italy; \\ v.parisi15@studenti.unisa.it \\ 2 Università degli Studi di Salerno, Ph. D. School of Pharmacy, 84084 Fisciano (SA), Italy \\ 3 Dipartimento di Scienze, Università della Basilicata, 85100 Potenza, Italy; antonio.vassallo@unibas.it \\ 4 Biogem, Research Institute "G. Salvatore”, 83031 Ariano Irpino (AV), Italy; \\ giacomo.signorino@biogem.it (G.S.); francesco.cardile@biogem.it (F.C.); milena.sorrentino@biogem.it (M.S.); \\ fabiana.colelli@biogem.it (F.C.); alessandra.fucci@biogem.it (A.F.); egildoluca.dandrea@biogem.it (E.L.D.) \\ 5 Dipartimento di Farmacia, Università di Pisa, 56126 Pisa, Italy; alessandra.braca@unipi.it (A.B.); \\ marinella.deleo@unipi.it (M.D.L.) \\ 6 Centro Interdipartimentale di Ricerca Nutraceutica e Alimentazione per la Salute "Nutrafood", \\ Università di Pisa, 56124 Pisa, Italy \\ * Correspondence: claudio.pisano@biogem.it (C.P.); detommasi@unisa.it (N.D.T.); \\ Tel.: +39-334-6817269 (C.P.); +39-089-969754 (N.D.T.)
}

Academic Editor: Gianni Sacchetti

Received: 11 April 2020; Accepted: 4 May 2020; Published: 11 May 2020

\begin{abstract}
Rheumatoid arthritis (RA) is a chronic inflammatory autoimmune disease characterized by the production of inflammatory factors. In order to overcome the side effects of currently used anti-inflammatory drugs, several attempts have been made to identify natural products capable of relieving RA symptoms. In this work, a herbal preparation consisting of propolis, pomegranate peel, and Aglianico grape pomace (PPP) extracts (4:1:1) was designed and evaluated for its effect on a murine collagen-induced arthritis (CIA) model. Firstly, the chemical contents of four different Italian propolis collected in the Campania region (Italy) were here reported for the first time. LC-MS analyses showed the presence of 38 constituents, identified in all propolis extracts, belonging to flavonoids and phenolic acids classes. The Pietradefusi extract was the richest one and thus was selected to design the PPP preparation for the in vivo assay. Our results highlight the impact of PPP on RA onset and progression. By using in vivo CIA models, the treatment with PPP resulted in a delayed onset of the disease and alleviated the severity of the clinical symptoms. Furthermore, we demonstrated that early PPP treatment was associated with a reduction in serum levels of IL-17, IL-1b, and IL-17-triggering cytokines.
\end{abstract}

Keywords: propolis; pomegranate; Aglianico grape pomace; herbal preparation; LC-ESI-MS/MS; rheumatoid arthritis; in vivo test

\section{Introduction}

Rheumatoid arthritis (RA) is an autoimmune disorder affecting about $1 \%$ of the global population, mainly women. Both genetic and environmental factors are involved in the development of this disease [1]. Clinically, RA manifests itself as a systemic, chronic inflammatory disease characterized by 
synovial inflammation and the erosion of bone and cartilage, which leads to the destruction of the affected joints, having an important impact on the individual quality of life in patients and also on social and economic aspects [2,3]. The cause of RA is unknown, but several studies have suggested the involvement of different molecular mechanisms. First of all, being an inflammatory disease, it involves several inflammatory cytokines, such as tumor necrosis factor- $\alpha$ (TNF- $\alpha)$, interleukin-1 (IL-1), interleukin-6 (IL-6), and interleukin-17 (IL-17), which are overexpressed in RA joints and play an important role in its pathogenesis [4,5]. RA treatment involves several approaches, including drugs of both synthetic and biological origins, causing different severe side effects ranging from osteoporosis to liver fibrosis and myocardial infarction; some of them also have quite an expensive price. Owing to these limitations, an increasing number of patients have started to turn to natural products to relieve the symptoms of RA [6,7]. Moreover, oxidative stress is considered to be involved in the pathogenesis of different diseases, such as atherosclerosis, cancer, neurodegenerative disorders, and autoimmune rheumatological diseases, including RA [8]. In this regard, research into natural product-based preparations with potential applications in RA could be important, with particular regard to the combination of two or more active products, which, acting through different mechanisms, may have an effect against the molecular mechanisms involved in RA, thus potentiating their efficacy and benefits [9]. Among the natural products, propolis, pomegranate (Punica granatum L., Punicaceae), and grape (Vitis vinifera L., Vitaceae) extracts have been subjected to an extensive scientific interest for their possible use in various pathologies, including those of inflammatory origin. In fact, their main components, consisting mainly of phenolic acids, flavonoids, and stilbenes, are promising candidates as therapeutic alternatives in the treatment of RA due to their strong anti-inflammatory activity reported in many in vitro and in vivo studies. The phenol content of both pomegranate and grape strongly depend on the cultivar and variety, as well as the climate and ecological conditions [10,11]. Several studies have reported that pomegranate peels from different geographic areas, including Italian regions, are rich in hydrolyzable tannins, with punicalagin as the main constituent [12]. The phenol content of red grape is characterized by phenolic acids, flavonols, anthocyanins, stilbenes, and condensed tannins, whose amount also remains high in grape pomace (winemaking byproduct) after the fermentation process [13]. These findings were also confirmed in Italian cultivars [14,15].

Propolis is one of the Apis mellifera L. elaborations obtained by the recollection of the exudate from different plant species. It is a complex mixture containing resin, balsam, waxes, volatiles, pollen, and, in a small proportion, secondary metabolites (5-10\%). Among the last, polyphenols, including flavonoids; phenolic acids and their esters; benzophenones; and lignans are the main components [16]. The propolis effective chemical composition as well as the type and number of bioactive compounds has been reported to be strongly dependent on and influenced by the source of the plant resin, seasons, and geographical origin. This mixture, used by honeybees as a defense against different predators, is nowadays recognized for its antimicrobial, antiviral, antioxidant, immunomodulatory, hepatoprotective, and anti-inflammatory activities, inhibiting the production of IL-17 and the differentiation of Th17 cells [17,18].

Through various different studies, it was proved that the proanthocyanidin-rich grape seed extract provides benefits against many diseases, i.e., inflammation, cardiovascular disease, hypertension, diabetes, cancer, peptic ulcers, and microbial infections $[19,20]$. A recent combination of two polyphenol-rich extracts, grape and propolis, potentiated anti-inflammatory activity in rats, reducing clinical scores with respect to the corticoid-treated group [21]. Moreover, several studies examined the effects of different pomegranate-related products, including extracts from peel, showing their large spectrum of anti-inflammatory activity [22,23]. Finally, pomegranate extract's administration in an RA model was shown to reduce oxidative stress, inhibit the p38-mitogen-activated protein kinase (p38-MAPK) pathway, and activate the transcription factor NF-кB [24].

In this context, Campania region (South Italy) folk medicine presents several uses of propolis. In particular, a traditional rural preparation of the internal area (Benevento and Avellino provinces) containing propolis and grape pomace was used in the past in the treatment of inflammation diseases 
such as body pain and oral inflammation. Based on this evidence, we can suppose that propolis, grape pomace, and P. granatum extracts could synergistically contribute to beneficial effects in the RA condition. This assumption is based on the fact that these extracts contain a variety of chemical compounds, including flavonoids, cinnamic acid derivatives, prenylated phenylpropanoids, and both ellagic and gallagic derivatives, showing immunomodulatory and anti-inflammatory effects and inhibiting some inflammatory modulator responses [2].

Thus, a traditional herbal preparation consisting of propolis, pomegranate peel, and grape pomace extracts (4:1:1) was concocted. The grape pomace was obtained from Aglianico, an ancient cultivar cultivated in southern Italy that was found to be very rich in phenol content [25]. The objective of this work was to perform a deep quali-quantitative chemical characterization of propolis coming from four different internal areas of the Campania region (Italy) and to evaluate the preventive and therapeutic efficacy of a natural product-based formulation containing propolis, pomegranate peel, and Aglianico grape pomace on a murine collagen-induced arthritis (CIA) model.

\section{Results and Discussion}

\subsection{Chemical Characterization of Extracts}

\subsubsection{Comparative Analysis of Four Different Italian Propolis}

The chemical contents of four different Italian propolis collected from hives located in the Campania region (the rural area of Pietradefusi, Melito Irpino, Melizzano, and Vallata) were herein established by HPLC coupled with a photodiode array (PDA)/UV and an electrospray ionization (ESI) mass spectrometer (MS) for the first time. ESI-MS chromatograms were registered in both negative (Figure 1) and positive ion modes (Figure 2), since propolis is a complex mixture containing different classes of compounds that can be detected using different techniques. In particular, the negative ion ESI-MS mode was suitable for the detection of phenolic acids and their esters, together with esters of pinobanksin.

In total, 38 constituents were identified in almost all propolis extracts, belonging to flavonoids and phenolic acids. The identification of all compounds was carried out comparing elution order, UV absorptions, and both full and fragmentation ESI-MS data of all detected molecules with those reported in previous studies [26-28]. Alpinetin, caffeic acid prenyl ester, luteolin, pinobanksin 5-methyl ether, pinobanksin 3-O-acetate, and quercetin were confirmed using reference standards. All these data are listed in Table 1 (ESI negative ion mode) and Table 2 (ESI positive ion mode).

Results of the LC-MS analyses showed that, with regard to the qualitative aspect, all the analyzed propolis extracts had very similar chemical profiles, with few differences about the distribution of some metabolites in the various samples. Flavonoids were found to be present in the form of aglycones, as well as expected in propolis since the glycoside forms are hydrolyzed by bees' glycosidase salivary enzymes [28]. In particular, the following classes of aglycones were found: flavones including chrysin, apigenin, luteolin, and galangin derivatives (compounds 2, 6, 7, 13, 15, 17, 21, 27, 28, 32, and 36); flavanones such as alpinetin (11) and pinocembrin (26); flavonols represented by quercetin, kaempferol, and isorhamnetin derivatives $(3,5,9,12,14,18,19$, and 29); dihydroflavonols including pinobanksin and their esters $(4,8,10,16,31,34,35,37$, and 38). Among phenolic acids, caffeic acid (1) and caffeic acid esters $(\mathbf{2 0}, \mathbf{2 3}, \mathbf{2 4}, \mathbf{3 0}$, and $\mathbf{3 3}$ ) were found as constituents in all propolis extracts. Compared to previous analyses of Italian propolis collected in different regions, such as Emilia Romagna [29] and Veneto [28], the chemical composition of Campanian propolis was found to be similar particularly in flavonoid content, whereas among phenolic acids, both ferulic and cinnamic acid derivatives were not found. 


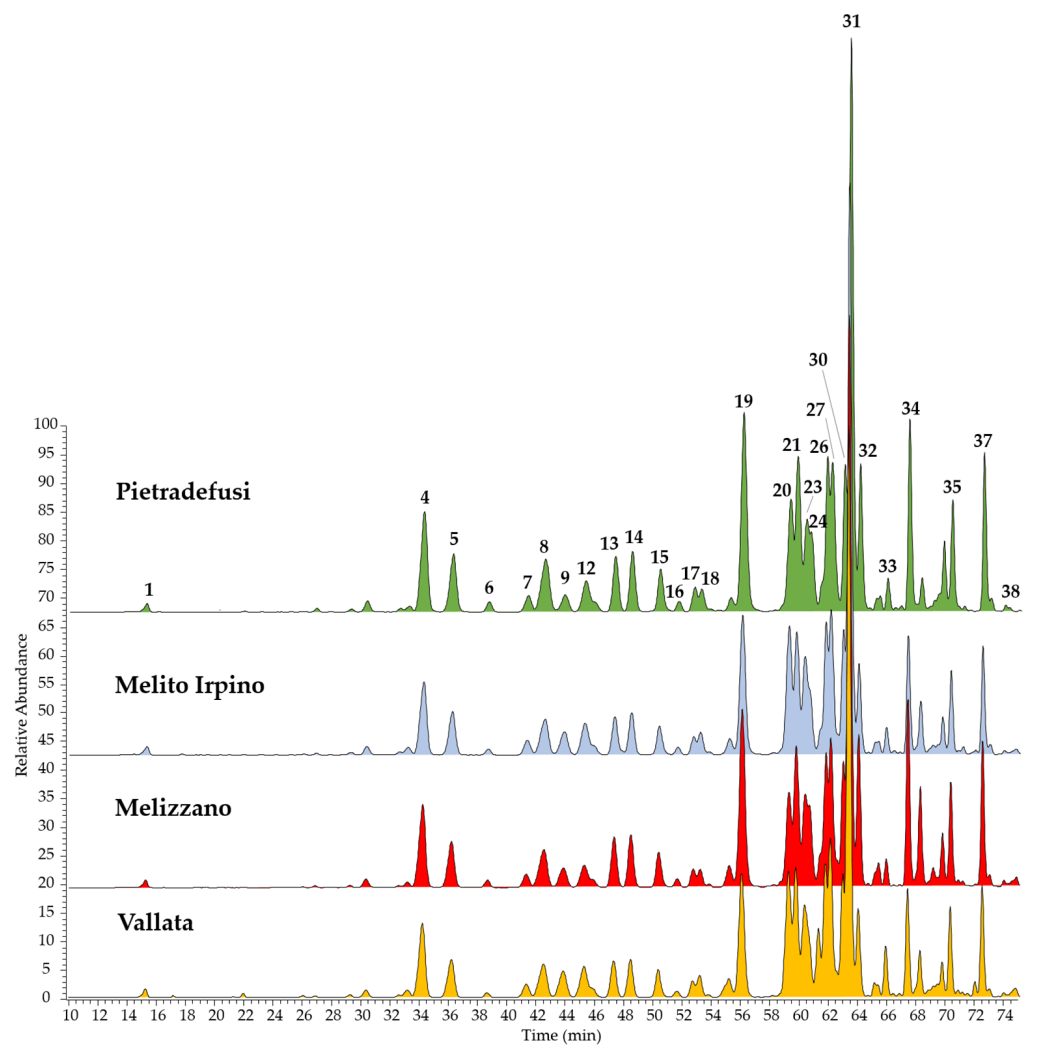

Figure 1. LC-ESI-MS/MS chromatograms, registered in negative ion mode, of four extracts of Italian propolis collected in the Campania region. Peak data are shown in Table 1.

Table 1. Chromatographic $\left(t_{\mathrm{R}}=\right.$ retention time), UV, and negative ion mode electrospray ionization-tandem mass spectrometry (ESI-MS/MS) data of the constituents identified in Italian propolis extracts: A, Pietradefusi; B, Melito Irpino; C, Melizzano; D, Vallata.

\begin{tabular}{|c|c|c|c|c|c|c|c|c|}
\hline Peak* & Compound & $\begin{array}{c}t_{\mathrm{R}} \\
(\mathrm{min})\end{array}$ & $\mathbf{M}$ & {$[\mathbf{M}-\mathbf{H}]^{-}$} & $\begin{array}{c}{[\mathrm{M}+} \\
\mathrm{HCOO}^{-}\end{array}$ & $\begin{array}{l}\text { ESI-MS/MS Product } \\
\text { Ions ** }\end{array}$ & $\begin{array}{c}\text { UV } \\
\left(\lambda_{\max }\right)\end{array}$ & Extract \\
\hline 1 & Caffeic acid & 15.1 & 180 & 179 & - & 135 & 243,324 & A-D \\
\hline 4 & Pinobanksin 5-methyl ether & 34.1 & 286 & 285 & 331 & $267,253,239,179,139$ & 236,287 & A-D \\
\hline 5 & Quercetin 3-methyl ether & 36.1 & 316 & 315 & - & $300,271,228$ & 256,357 & A-D \\
\hline 6 & Chrysin 5-methyl ether & 38.6 & 268 & 267 & 313 & 252,224 & 264,319 & A-D \\
\hline 7 & Apigenin & 41.2 & 270 & 269 & 315 & $225,151,117$ & 268,335 & A-D \\
\hline 8 & Pinobanksin & 42.4 & 272 & 271 & 317 & $253,243,165,107$ & 236,291 & A-D \\
\hline 9 & Kaempferol & 43.7 & 286 & 285 & 331 & 257,241 & 269,364 & A-D \\
\hline 12 & Isorhamnetin & 45.2 & 316 & 315 & 361 & 300, 151 & 255,370 & A-D \\
\hline 13 & Luteolin 3'-methyl ether & 47.2 & 300 & 299 & 345 & $284,256,151$ & 267,351 & A-D \\
\hline 14 & Quercetin dimethyl ether & 48.4 & 330 & 329 & 375 & $314,299,285,243$ & 255,356 & A-D \\
\hline 15 & Galangin 5-methyl ether & 50.3 & 284 & 283 & 329 & 268,239 & $260,300,351$ & A-D \\
\hline 16 & Pinobanksin 5-methyl ether-3-O-acetate & 51.2 & 328 & 327 & 373 & $285,267,252,224$ & 309 & A-D \\
\hline 17 & Luteolin methyl ether & 52.7 & 300 & 299 & - & 284 & 268,347 & A-D \\
\hline 18 & Quercetin 7-methyl ether & 53.1 & 316 & 315 & 361 & $300,271,256,193,165$ & 256,368 & A-D \\
\hline 19 & Quercetin dimethyl ether & 56.0 & 330 & 329 & - & 314,299 & 256,357 & A-D \\
\hline 20 & Caffeic acid prenyl ester & 59.2 & 248 & 247 & 293 & 179,135 & 245,326 & A-D \\
\hline 21 & Chrysin & 59.7 & 254 & 253 & - & 254,209 & 268,321 & A-D \\
\hline 23 & Caffeic acid benzyl ester & 60.3 & 270 & 269 & - & 178,134 & 295,320 & A-D \\
\hline 24 & Caffeic acid prenyl ester & 60.6 & 248 & 247 & 293 & $\mathbf{1 7 9}, 203,135$ & 245,327 & A-D \\
\hline 26 & Pinocembrin & 61.7 & 256 & 255 & 300 & $300,213,187,151,145$ & 237,289 & $\mathrm{~A}-\mathrm{C}$ \\
\hline 27 & Galangin & 62.1 & 270 & 269 & 315 & $269,227,197$ & 266,359 & $\mathrm{~A}-\mathrm{C}$ \\
\hline 30 & Caffeic acid phenylethyl ester (CAPE) & 62.9 & 284 & 283 & 329 & $\mathbf{1 7 9}, 135$ & 301,326 & $\mathrm{~A}-\mathrm{C}$ \\
\hline 31 & Pinobanksin 3-O-acetate & 63.3 & 314 & 313 & 359 & $271,253,209$ & 237,293 & $\mathrm{~A}-\mathrm{C}$ \\
\hline 32 & Methoxychrysin & 64.0 & 284 & 283 & 329 & $268,239,211$ & 266,335 & A-D \\
\hline 33 & Caffeic acid cinnamyl ester & 65.9 & 296 & 295 & 341 & $251,211,178,134$ & $248,301,313$ & A-D \\
\hline 34 & Pinobanksin 3-O-propionate & 67.3 & 328 & 327 & 373 & 271,253 & 293 & A-D \\
\hline 35 & Pinobanksin 3-O-butyrate & 70.3 & 342 & 341 & - & 271,253 & 248,292 & A-D \\
\hline 37 & Pinobanksin 3-O-pentanoate & 72.5 & 356 & 355 & 401 & 271,253 & 292 & A-D \\
\hline 38 & Pinobanksin 3-O-hexanoate & 73.9 & 370 & 369 & - & 271,253 & 292 & A-D \\
\hline
\end{tabular}

* Compounds are listed in order of increasing $t_{\mathrm{R}}$ and numbers correspond with the peak numbers in Figure 1. ** Product ions are generated by the fragmentation of $[\mathrm{M}-\mathrm{H}]^{-}$; the base ion peaks generated in the ESI-MS/MS experiments are shown in bold. 


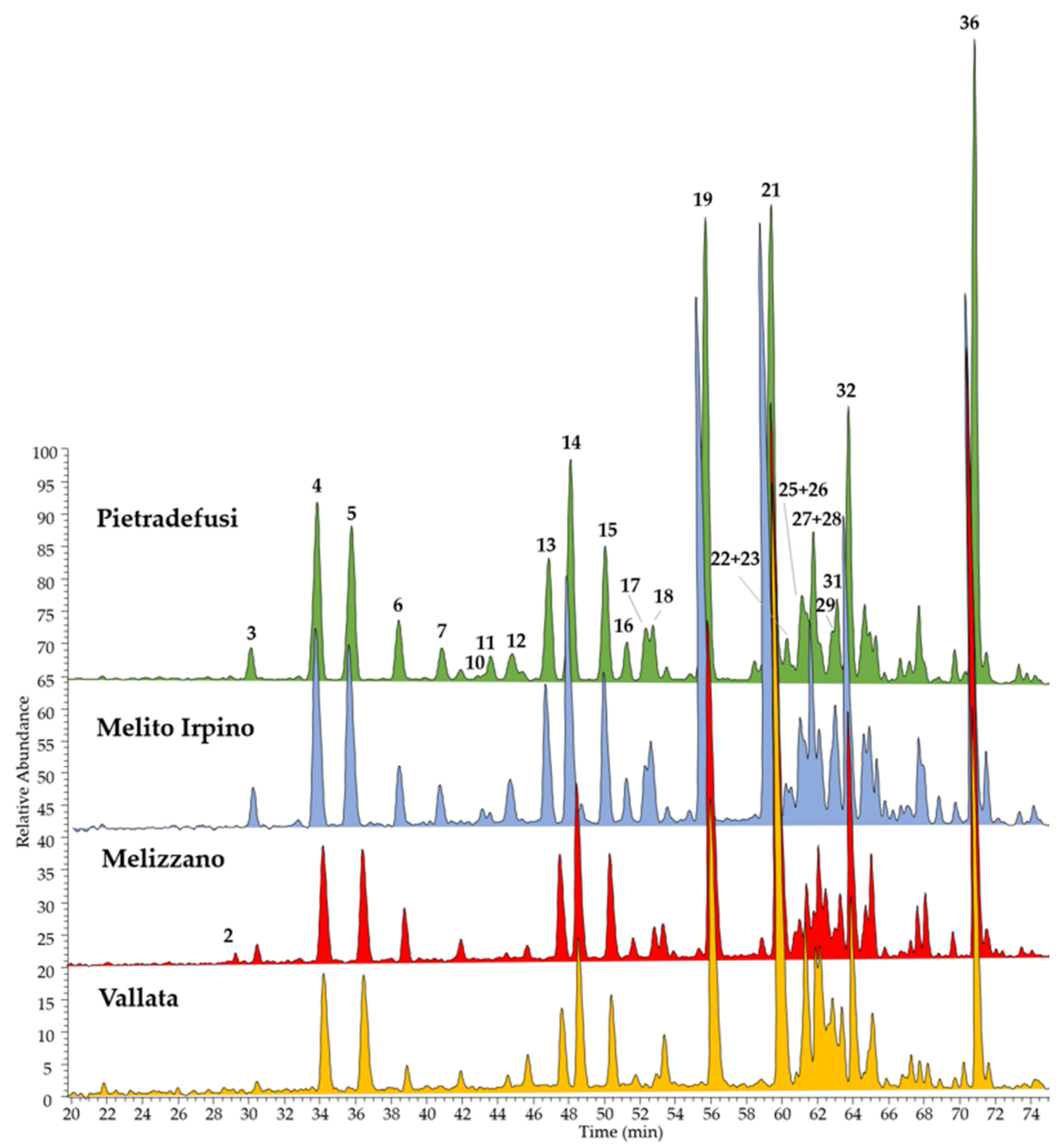

Figure 2. LC-ESI-MS/MS chromatograms, registered in positive ion mode, of four extracts of Italian propolis collected in Campania Region. Peak data are shown in Table 2.

Quantitative analyses evidenced that the total phenol content in the studied propolis extracts was in the range of $15.54-39.18 \%$ (Table 3), with Pietradefusi extract the richest one. In contrast, the propolis collected at Vallata presented a minor content in terms of total phenols, but it was the only extract in which the total phenolic acids were higher than the total flavonoids. Taking into account that phenolic acids were represented by six compounds, whereas quantified flavonoids were 30 different compounds, the estimated amount of caffeic acid derivatives in the propolis is very relevant, with caffeic acid phenylethyl ester (CAPE, compound 30) and caffeic acid prenyl esters (20 and 24) the most representative. Among flavonoids, chrysin (21) and chrysin 5-methyl ether (36) were the most abundant in all extracts. Other main flavonoids were represented by quercetin dimethyl ether (19); galangin 5-methyl ether (15); pinobanksin (8); and pinobanksin esters such as pinobanksin 3-O-acetate (31) and pinobanksin 3-O-hexanoate (38). These results are in agreement with previous studies on Italian propolis that showed a very similar profile, with variability in total phenol content among the different samples [27]. 
Table 2. Chromatographic ( $t_{\mathrm{R}}=$ retention time), UV, and positive ion mode ESI-MS/MS data of the constituents identified in Italian propolis extracts: A, Pietradefusi; B, Melito Irpino; C, Melizzano; D, Vallata.

\begin{tabular}{|c|c|c|c|c|c|c|}
\hline Peak* & Compound & $\begin{array}{c}t_{\mathrm{R}} \\
(\mathrm{min})\end{array}$ & {$[\mathbf{M}+\mathbf{H}]^{+}$} & $\begin{array}{c}\text { ESI-MS/MS } \\
\text { Product Ions }\end{array}$ & $\begin{array}{c}\mathrm{UV} \\
\left(\lambda_{\max }\right)\end{array}$ & Extract \\
\hline 2 & Luteolin methyl ether & 29.1 & 301 & 286 & 259,358 & $\mathrm{C}$ \\
\hline 3 & Quercetin dimethyl ether & 30.3 & 331 & 316,301 & 252,362 & A-D \\
\hline 4 & Pinobanksin 5-methyl ether & 33.8 & 287 & $269, \mathbf{2 4 1}, 91$ & 288 & A-D \\
\hline 5 & Quercetin 3-methyl ether & 35.7 & 317 & $302,165,153,137$ & 256,357 & A-D \\
\hline 6 & Chrysin 5-methyl ether & & 269 & 254,167 & 262,329 & A-D \\
\hline 7 & Apigenin & 40.7 & 271 & 247,153 & 268,337 & A-D \\
\hline 10 & Pinobanksin methyl ether & 43.0 & 287 & 269,241 & 266,366 & B-D \\
\hline 11 & Alpinetin & 43.6 & 271 & 167,131 & 268,365 & A, D \\
\hline 12 & Isorhamnetin & 44.6 & 317 & $302,285,261,257$ & 254,370 & $\mathrm{~A}, \mathrm{C}$ \\
\hline 13 & Luteolin $3^{\prime}$-methyl ether & 46.8 & 301 & 286 & 267,350 & A-D \\
\hline 14 & Quercetin dimethyl ether & 48.0 & 331 & $316,301,299$ & 253,355 & A-D \\
\hline 15 & Galangin 5-methyl ether & 50. 0 & 285 & 270,167 & 260,352 & A-D \\
\hline 16 & $\begin{array}{l}\text { Pinobanksin 5-methyl } \\
\text { ether-3-O-acetate }\end{array}$ & 51.2 & 329 & $287,269,241,167$ & 289,329 & A-D \\
\hline 17 & Luteolin methyl ether & 52.2 & 301 & 286 & 266,348 & A-D \\
\hline 18 & Quercetin 7-methyl ether & 52.6 & 317 & $\begin{array}{c}302,299,271,243 \\
179,167\end{array}$ & 256,370 & A-D \\
\hline 19 & Quercetin dimethyl ether & 55.6 & 331 & 316,299 & 256,356 & A-D \\
\hline 21 & Chrysin & 59.3 & 255 & $209,153,129$ & 268,314 & A-D \\
\hline 22 & Flavonoid aglycon methyl ether & 60.1 & 285 & 270 & 245,327 & B-D \\
\hline 25 & Flavonoid aglycon methyl ether & 61.0 & 285 & 270 & 272,318 & A-D \\
\hline 26 & Pinocembrin & 61.3 & 257 & $215,153, \mathbf{1 3 1}, 103$ & 290 & A-D \\
\hline 27 & Galangin & 61.7 & 271 & 165,153 & 246,327 & A-D \\
\hline 28 & Luteolin methyl ether & 62.1 & 301 & 286 & 268,362 & A-D \\
\hline 29 & Quercetin dimethyl ether & 62.8 & 331 & 316,299 & 296,326 & A-D \\
\hline 31 & Pinobanksin 3-O-acetate & 63.0 & 315 & $273,255,227,153$ & 296,326 & A-D \\
\hline 32 & Methoxychrysin & 63.7 & 285 & 270,242 & 293 & A-D \\
\hline 36 & Chrysin 5-methyl ether & 70.8 & 269 & 254,167 & 289 & A-D \\
\hline
\end{tabular}

* Compounds are listed in order of increasing $t_{\mathrm{R}}$ and numbers correspond with the peak numbers in Figure 2 . ** Product ions are generated by the fragmentation of $[\mathrm{M}+\mathrm{H}]^{+}$; the base ion peaks generated in the ESI-MS/MS experiments are shown in bold.

Table 3. Quantitative amount $(\mathrm{g} / 100 \mathrm{~g} \pm$ standard deviation of raw propolis) of constituents detected in the propolis extracts.

\begin{tabular}{|c|c|c|c|c|c|}
\hline Peak & Compound & Pietradefusi & Melito Irpino & Melizzano & Vallata \\
\hline 1 & Caffeic acid & $0.308 \pm 0.01$ & $0.273 \pm 0.01$ & $0.150 \pm 0.03$ & $0.203 \pm 0.01$ \\
\hline 3 & Quercetin dimethyl ether & $0.014 \pm 0.00$ & $0.010 \pm 0.00$ & $0.005 \pm 0.00$ & Trace * \\
\hline 4 & Pinobanksin 5-methyl ether & $0.971 \pm 0.01$ & $0.557 \pm 0.05$ & $0.354 \pm 0.03$ & $0.219 \pm 0.01$ \\
\hline 5 & Quercetin 3-methyl ether & $0.843 \pm 0.04$ & $0.288 \pm 0.01$ & $0.252 \pm 0.01$ & $0.092 \pm 0.00$ \\
\hline 6 & Chrysin 5-methyl ether & $0.612 \pm 0.01$ & $0.309 \pm 0.03$ & $0.260 \pm 0.01$ & $0.103 \pm 0.01$ \\
\hline 7 & Apigenin & $0.378 \pm 0.01$ & $0.240 \pm 0.02$ & $0.179 \pm 0.09$ & $0.103 \pm 0.02$ \\
\hline 8 & Pinobanksin & $1.226 \pm 0.12$ & $0.620 \pm 0.00$ & $0.542 \pm 0.06$ & $0.477 \pm 0.03$ \\
\hline 9 & Kaempferol & $0.038 \pm 0.00$ & $0.021 \pm 0.00$ & $0.012 \pm 0.00$ & $0.031 \pm 0.00$ \\
\hline 10 & Pinobanksin methyl ether & $0.126 \pm 0.01$ & $0.149 \pm 0.02$ & $0.071 \pm 0.01$ & $0.089 \pm 0.01$ \\
\hline 11 & Alpinetin & $0.221 \pm 0.00$ & $0.127 \pm 0.00$ & $0.069 \pm 0.01$ & $0.053 \pm 0.00$ \\
\hline 12 & Isorhamnetin & $0.267 \pm 0.01$ & $0.141 \pm 0.01$ & $0.020 \pm 0.00$ & $0.011 \pm 0.00$ \\
\hline 13 & Luteolin 3'-methyl ether & $0.656 \pm 0.00$ & $0.361 \pm 0.02$ & $0.299 \pm 0.02$ & $0.170 \pm 0.01$ \\
\hline 14 & Quercetin dimethyl ether & $0.791 \pm 0.03$ & $0.272 \pm 0.01$ & $0.281 \pm 0.01$ & $0.051 \pm 0.00$ \\
\hline 15 & Galangin 5-methyl ether & $1.217 \pm 0.00$ & $0.653 \pm 0.00$ & $0.494 \pm 0.00$ & $0.265 \pm 0.00$ \\
\hline 16 & $\begin{array}{l}\text { Pinobanksin 5-methyl } \\
\text { ether-3-O-acetate }\end{array}$ & $0.030 \pm 0.00$ & $0.020 \pm 0.00$ & $0.013 \pm 0.00$ & $0.012 \pm 0.00$ \\
\hline 17 & Luteolin methyl ether & $0.479 \pm 0.02$ & $0.279 \pm 0.03$ & $0.143 \pm 0.01$ & $0.076 \pm 0.08$ \\
\hline 18 & Quercetin 7-methyl ether & $0.374 \pm 0.02$ & $0.101 \pm 0.00$ & $0.051 \pm 0.00$ & $0.047 \pm 0.00$ \\
\hline 19 & Quercetin dimethyl ether & $1.981 \pm 0.13$ & $0.704 \pm 0.05$ & $0.754 \pm 0.03$ & $0.278 \pm 0.01$ \\
\hline 20 & Caffeic acid prenyl ester I & $3.930 \pm 0.13$ & $3.682 \pm 0.05$ & $1.779 \pm 0.36$ & $2.973 \pm 0.12$ \\
\hline
\end{tabular}


Table 3. Cont.

\begin{tabular}{cccccc}
\hline Peak & Compound & Pietradefusi & Melito Irpino & Melizzano & Vallata \\
\hline $\mathbf{2 1}$ & Chrysin & $4.535 \pm 0.06$ & $2.743 \pm 0.08$ & $2.267 \pm 0.14$ & $1.452 \pm 0.08$ \\
$\mathbf{2 2}$ & Flavonoid aglycon methyl ether & $0.323 \pm 0.00$ & $0.146 \pm 0.01$ & $0.097 \pm 0.01$ & $0.046 \pm 0.01$ \\
$\mathbf{2 3}$ & Caffeic acid benzyl ester & $3.220 \pm 028$ & $2.186 \pm 0.11$ & $0.914 \pm 0.13$ & $1.990 \pm 0.14$ \\
$\mathbf{2 4}$ & Caffeic acid prenyl ester II & $3.695 \pm 0.02$ & $2.750 \pm 0.09$ & $2.032 \pm 0.28$ & $1.574 \pm 0.03$ \\
$\mathbf{2 5}$ & Flavonoid aglycon methyl ether & $0.676 \pm 0.03$ & $0.392 \pm 0.01$ & $0.256 \pm 0.04$ & $0.040 \pm 0.00$ \\
$\mathbf{2 6}$ & Pinocembrin & $0.594 \pm 0.02$ & $0.387 \pm 0.01$ & $0.203 \pm 0.02$ & $0.140 \pm 0.08$ \\
$\mathbf{2 7}$ & Galangin & $0.983 \pm 0.01$ & $0.662 \pm 0.00$ & $0.351 \pm 0.01$ & $0.202 \pm 0.03$ \\
$\mathbf{2 8}$ & Luteolin methyl ether & $0.295 \pm 0.01$ & $0.389 \pm 0.02$ & $0.300 \pm 0.03$ & $0.168 \pm 0.00$ \\
$\mathbf{2 9}$ & Quercetin dimethyl ether & $0.139 \pm 0.00$ & $0.181 \pm 0.00$ & $0.466 \pm 0.00$ & $0.016 \pm 0.00$ \\
$\mathbf{3 0}$ & Caffeic acid phenylethyl ester (CAPE) & $4.100 \pm 0.26$ & $2.787 \pm 0.07$ & $1.811 \pm 0.30$ & $2.088 \pm 0.13$ \\
$\mathbf{3 1}$ & Pinobanksin 3-O-acetate & $1.415 \pm 0.09$ & $1.139 \pm 0.02$ & $0.747 \pm 0.13$ & $0.925 \pm 0.06$ \\
$\mathbf{3 2}$ & Methoxychrysin & $1.030 \pm 0.01$ & $0.590 \pm 0.01$ & $0.553 \pm 0.05$ & $0.249 \pm 0.02$ \\
$\mathbf{3 3}$ & Caffeic acid cinnamyl ester & $1.08 \pm 0.07$ & $0.715 \pm 0.03$ & $0.438 \pm 0.09$ & $0.910 \pm 0.09$ \\
$\mathbf{3 4}$ & Pinobanksin 3-O-propionate & $0.471 \pm 0.03$ & $0.249 \pm 0.01$ & $0.255 \pm 0.04$ & $0.177 \pm 0.02$ \\
$\mathbf{3 5}$ & Pinobanksin 3-O-butyrate & $0.292 \pm 0.02$ & $0.176 \pm 0.01$ & $0.143 \pm 0.03$ & $0.137 \pm 0.01$ \\
$\mathbf{3 6}$ & Chrysin 5-methyl ether & $4.450 \pm 0.13$ & $1.642 \pm 0.05$ & $1.884 \pm 0.10$ & $0.705 \pm 0.70$ \\
$\mathbf{3 7}$ & Pinobanksin 3-O-pentanoate & $0.509 \pm 0.04$ & $0.289 \pm 0.01$ & $0.261 \pm 0.04$ & $0.231 \pm 0.02$ \\
$\mathbf{3 8}$ & Pinobanksin 3-O-hexanoate & $1.415 \pm 0.00$ & $0.012 \pm 0.00$ & $0.014 \pm 0.00$ & $0.009 \pm 0.00$ \\
& Total flavonoids & $22.85 \pm 0.86$ & $12.99 \pm 0.49$ & $10.92 \pm 0.92$ & $5.800 \pm 1.23$ \\
& Total phenolic acids & $16.33 \pm 0.70$ & $12.40 \pm 0.37$ & $7.124 \pm 0.92$ & $9.739 \pm 0.53$ \\
& Total phenols & $39.18 \pm 1.56$ & $25.39 \pm 0.86$ & $18.04 \pm 1.84$ & $15.54 \pm 1.76$ \\
\hline
\end{tabular}

Pietradefusi propolis extract was the richest one and was thus selected to design the herbal preparation PPP for the in vivo assay.

\subsubsection{Chemical Content of Pomegranate Peel and Grape Pomace}

The pomegranate peel and grape pomace extracts used in the phytopreparation were characterized by LC-MS/MS analyses. All the compounds were tentatively identified by the comparison of spectral and chromatographic data with those of previous studies. According to the literature [30], the main constituents of pomegranate peel were established to be derivatives of ellagic acid (ellagitannins) and gallagic acid (gallagyl esters) (Table 4). Ellagic acid $\left(\lambda_{\max }\right.$ at 254 and $368 \mathrm{~nm}$ ) showed a deprotonated molecule at $[\mathrm{M}-\mathrm{H}]^{-}$at $\mathrm{m} / \mathrm{z} 301$; accordingly, in the MS/MS experiments on the detected ellagitannins, a base ion peak at $\mathrm{m} / \mathrm{z} 301$ was observed. Most of the compounds were in glycoside form, as deduced by the loss of hexosyl $(162 \mathrm{u})$ or pentosyl $(132 \mathrm{u})$ units. The gallagyl derivatives were tentatively identified as punicalin $\left([\mathrm{M}-\mathrm{H}]^{-}\right.$at $\left.m / z 781\right)$ and punicalagin $\left([\mathrm{M}-2 \mathrm{H}]^{2-}\right.$ at $\left.m / z 541\right)$, two gallagyl esters previously found to be the main components in pomegranate and occurring in the form of two isomers [31].

Grape pomace was found to be very rich in the phenolic compounds such as resveratrol, flavonols (quercetin, laricitrin, syringetin, and myricetin glucosides), many anthocyanins (cyanidin, delphinidin, malvidin, and petunidin derivatives), and flavan-3-ols (catechin/epicatechin and their procyanidin oligomers), in agreement with previous studies (Table 5) [32-36].

\subsection{Murine RA Model Assay}

To verify if a herbal preparation consisting of propolis, pomegranate peel, and grape pomace extracts (4:1:1) (hereafter PPP mixture) could have a therapeutic potential in inflammation, CIA mice were treated using two different treatment schedules (Figure 3a).

Both strategies reduced the disease severity, both when administered early at the induction of arthritis (Group 3) and when administered after CIA establishment (Group 4).

More specifically, the treatment with the PPP mixture ameliorated paw swelling and lowered the incidence (number of affected paws) and symptoms (severity score) in CIA mice (Figure 3b-d). 
Table 4. Main components of the pomegranate peel extract.

\begin{tabular}{|c|c|c|c|}
\hline Compound & {$[\mathbf{M}-\mathbf{H}]^{-}$} & ESI-MS/MS Product Ions * & $\begin{array}{c}\text { UV } \\
\left(\lambda_{\max }\right)\end{array}$ \\
\hline \multicolumn{4}{|l|}{ Pomegranate } \\
\hline \multicolumn{4}{|l|}{ Ellagitannins } \\
\hline Ellagic acid & 301 & 229,173 & 254,368 \\
\hline Ellagic acid pentoside & 433 & 301,285 & 254,363 \\
\hline Ellagic acid hexoside & 463 & 301 & 253,362 \\
\hline HHDP-hexoside & 481 & 301,275 & 237 \\
\hline Galloyl-HHDP-hexose & 633 & $463,301,275$ & 235,257 \\
\hline Ellagic acid derivative & 799 & $781,479,301$ & 235,259 \\
\hline Galloyl-HHDP-DHHDP-hexose (granatin B) & 952 & $933,915,613,445,301$ & 237,261 \\
\hline Castalagin derivative & 965 & $933,915,781,631,445,301$ & 242,269 \\
\hline \multicolumn{4}{|l|}{ Gallagyl derivatives } \\
\hline Gallagyl-hexose (punicalin isomer I) & 781 & $721,601,575,449,299$ & $223,259,376$ \\
\hline Gallagyl-hexose (punicalin isomer II) & 781 & $721,601,575,449,299$ & $234,259,380$ \\
\hline HHDP-gallagyl-hexose (punicalagin isomer I) & $541 * *$ & $781,601,575, \mathbf{3 0 1}, 275$ & $235,259,380$ \\
\hline HHDP-gallagyl-hexose (punicalagin isomer II) & $541 * *$ & $781,601,575, \mathbf{3 0 1}, 275$ & $236,258,379$ \\
\hline
\end{tabular}

DHHDP $=$ dehydrohexahydroxydiphenic acid; HHDP $=$ bis-hexahydroxydiphenoyl hexoside. ${ }^{*}$ Base ion peaks are shown in bold. ${ }^{* *}$ Doubly charged ion species $[\mathrm{M}-2 \mathrm{H}]^{2-}$ corresponding to $1084 \mathrm{u}$.

Table 5. Main components of the Aglianico grape pomace extract.

\begin{tabular}{cccc}
\hline Compound & HR-[M + H] $]^{+}[\mathbf{M}]^{+}$ & $\begin{array}{c}\text { HR-ESI-MS/MS } \\
\text { Product Ions }\end{array}$ & Error (ppm) \\
\hline Phenolics & & & \\
Resveratrol & 229.0858 & 211,135 & -0.43 \\
Catechin/epicatechin & 291.0860 & $165,139,123$ & -1.03 \\
Quercetin & 303.0499 & $257,229,165,137$ & -0.01 \\
Cyanidin 3-O-glucoside & $449.1070^{*}$ & 287 & -1.78 \\
Delphinidin 3-O-glucoside & $465.1022^{*}$ & 303 & -1.07 \\
Petunidin 3-O-glucoside & $479.1176^{*}$ & 317 & -1.67 \\
Quercetin 3-O-glucuronide & 479.0812 & 303 & -1.67 \\
Malvidin 3-O-glucoside & $493.1329^{*}$ & 331 & -2.23 \\
Myricetin 3-O-glucuronide & 495.0751 & 319 & -3.64 \\
Laricitricin 3-O-glucoside & $495.1127^{*}$ & 333 & -1.21 \\
Syringetin 3-O-glucoside & 509.1278 & 347 & -2.36 \\
Malvidin 3-O-acetylglucoside & $517.1331^{*}$ & 355 & -1.74 \\
Procyanidin dimer & $535.1430^{*}$ & 331 & -2.99 \\
Procyanidin dimer & $561.1223^{*}$ & 399 & -2.85 \\
Vitisin A (malvidin-3-O-glucoside pyruvate) & 579.1476 & 427,291 & -3.63 \\
Malvidin 3-O-p-coumaroylglucoside & 595.1439 & 443,291 & -1.18 \\
Malvidin 3-O-glucoside-ethyl-(epi)catechin & $639.1699^{*}$ & 331 & -1.41 \\
Procyanidin trimer & $809.2177^{*}$ & $647,519,357$ & -1.41 \\
Malvidin & 867.2130 & 579,427 & -0.11 \\
3-O-p-coumaroylglucoside-ethyl-(epi)catechin & $955.2630^{*}$ & 665,357 & -2.62 \\
\hline
\end{tabular}

$\mathrm{HR}=$ high-resolution. ${ }^{*}$ The molecular ion is represented by $[\mathrm{M}]^{+}$.

The early treatment with PPP mixture reduced the number of affected paws by $60 \%$ with respect to CIA-induced mice (6/20 in Group 3 vs. 16/20 in Group 2). A 30\% reduction in affected paws (11/20 affected paws) was instead observed when treatment started 30 days after the CIA induction, when the pathology was well established. In the treated groups, there was also a significant reduction in the severity score and the associated inflammatory state. Indeed, the mean severity score was 1.95 in collagen-induced mice (Group 2), 0.85 in early PPP-treated mice (Group 3), and 1.2 in mice treated after the RA onset (Group 4). The severity score measured for each paw is reported in Figure 3e. 
A

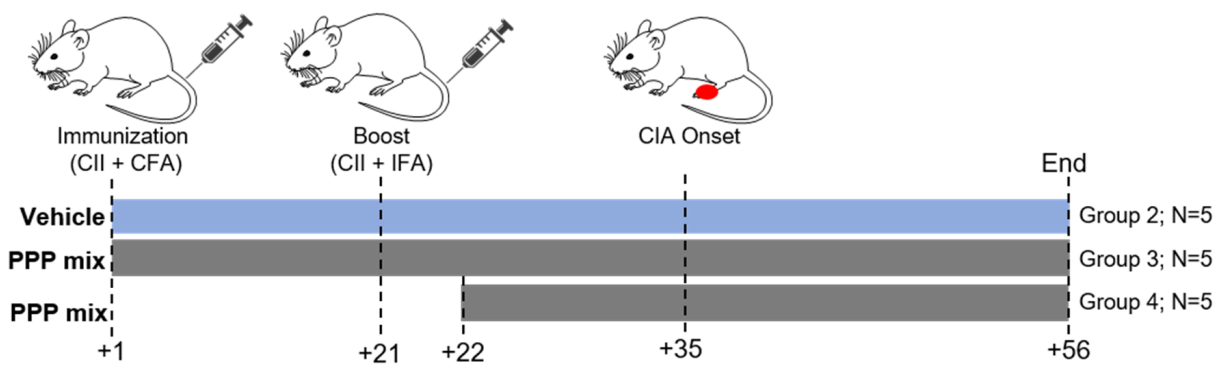

B

FORELIMBS

HINDLIMBS

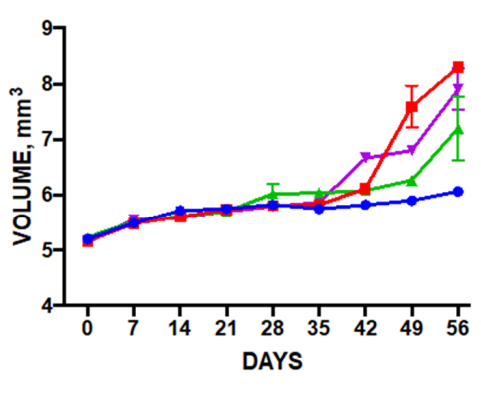

C

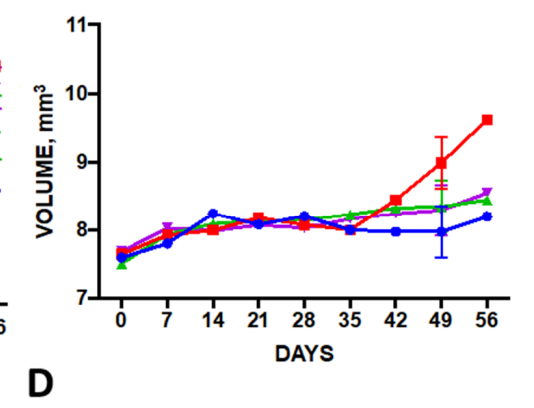

$\rightarrow$ Group 1

- Group 2

+ Group 3

$\rightarrow$ Group 4
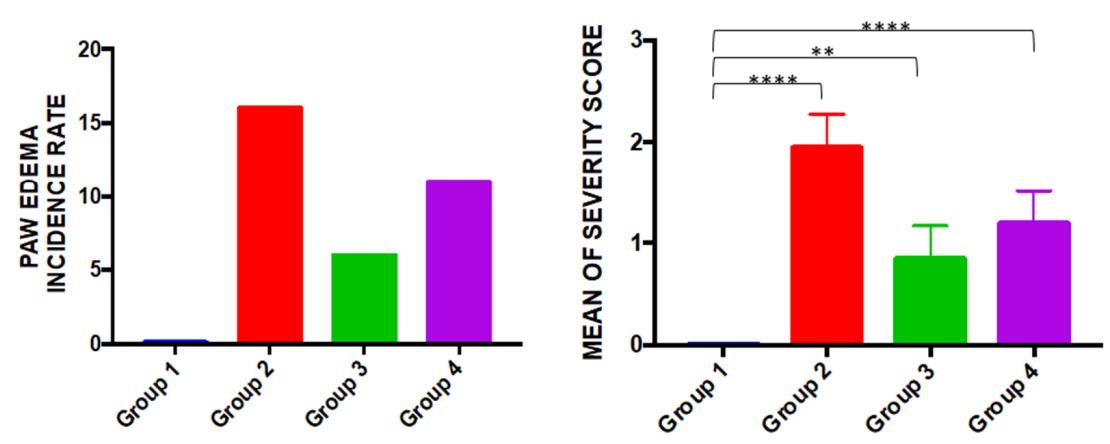

E

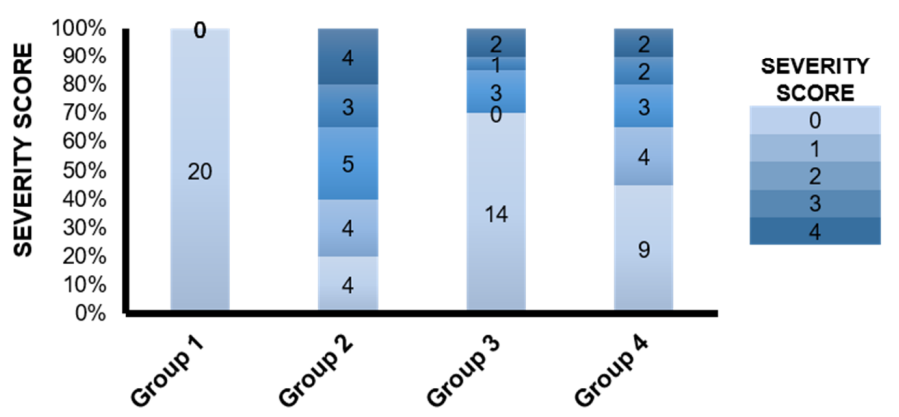

Figure 3. Treatment with PPP (propolis, pomegranate, and grape pomace) mixture ameliorates the pathology of collagen-induced arthritis (CIA). (A) Timetable of CIA induction and treatment strategies in type II collagen (CII)-immunized DBA/1J mice. All mice were sacrificed on day 56 post immunization. (B) The average forepaw and hindpaw volumes were measured in each experimental group. (C) Incidence of rheumatoid arthritis (RA) (number of paws showing clinical sympthoms). (D) Severity score observed in each experimental group (mean \pm SEM). (E) Distribution of the severity scores among the experimental groups. Data are from $\mathrm{n}=5$ mice/group $\left(\mathrm{n}=20\right.$ paws/group). ${ }^{* *} p<0.01$; $* * * * x<0.0001$, as calculated by one-way ANOVA. CII = collagen II; CFA = Complete Freund Adjuvant; IFA = Incomplete Freund Adjuvant. 
Proinflammatory cytokines, and in particular IL-17, IL-6, and IL-1b, are implicated in the pathogenesis of RA. Recent in vivo animal models and in vitro human studies demonstrated that proinflammatory cytokines play a crucial role and IL-17 can be considered a decisive mediator in the pathogenesis of RA [37]. The ELISA results confirmed a significant upregulation of IL-17 and IL-1b in collagen-induced mice (Group 2); a similar trend was also observed for IL-6. Hence, we asked whether the treatment with PPP mixture inhibited the expression of these proinflammatory factors in vivo. The early administration of the PPP mixture (Group 3) prevents IL-17 and IL-1b increases induced by the collagen II administration, while it does not affect IL-6 levels (Figure 4). The treatment with PPP after the RA onset in mice (Group 4) does not restore the cytokines' profile, suggesting that the treatment with PPP exerts major protective effects on the RA onset (by limiting IL-17 and IL-17-triggering cytokine IL-1b production), while it only exhibits a partial therapeutic effect. Previous studies published in the literature on the efficacy of plant extracts in reducing the onset and progression of RA in a CIA model reported significant effects with a dosage of $200 \mathrm{mg} / \mathrm{kg}[38,39]$ of tested extract, and in other cases up to $500 \mathrm{mg} / \mathrm{kg}$ [40]. Compared to these results, the PPP mixture, exerting its action at dose $150 \mathrm{mg} / \mathrm{kg}$, can be considered a promising potential agent for managing RA.

A

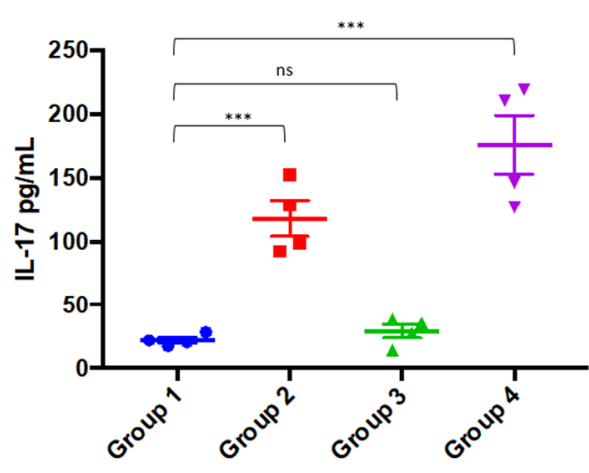

C

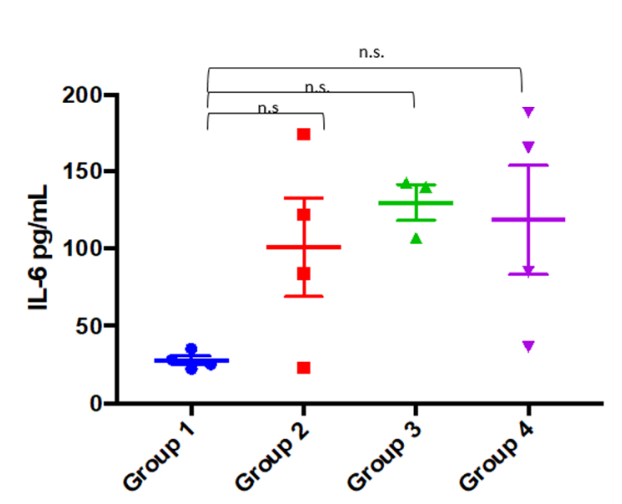

B

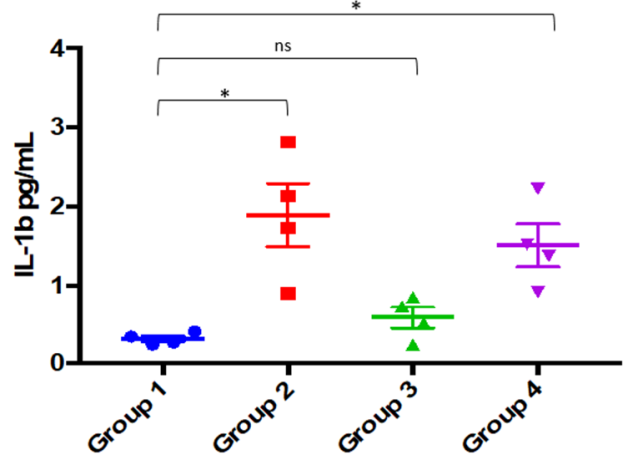

Figure 4. PPP (propolis, pomegranate, and grape pomace) mixture inhibits the expression of IL-17 and IL-1b. IL-17 (A), IL-1b (B), and IL-6 (C) levels measured in each sample of the indicated experimental groups. Symbols refer to the cytokine levels measured in each sample; horizontal lines indicate mean values \pm SEM for each group. ${ }^{*} p<0.05 ;{ }^{* * *} p<0.001 ; \mathrm{ns} / \mathrm{n} . \mathrm{s} .=$ not significant, as calculated using one-way ANOVA. 


\section{Materials and Methods}

\subsection{Chemicals}

The HPLC-grade ethanol, acetonitrile, and formic acid were purchased from VWR International srl (Milano, Italy). The HPLC-grade water $(18 \mathrm{~mW})$ was prepared by a Milli-Q purification system (Millipore Co., Bedford, MA, USA). The quercetin reference standard was purchased from Sigma-Aldrich S.p.a. (Milano, Italy). The alpinetin, caffeic acid prenyl ester, luteolin, pinobanksin 5-methyl ether, and pinobanksin 3-O-acetate used as reference standards were isolated from the propolis extract by size exclusion column chromatography (Sephadex LH-20, $5 \times 100 \mathrm{~cm}$, flow rate $1.0 \mathrm{~mL} / \mathrm{min}$ ) eluting with methanol, followed by RP-HPLC using a $C_{18} \mu$-Bondapak column-30 $\mathrm{cm} \times 7.8 \mathrm{~mm}, 10 \mu \mathrm{m}$ (Waters, Milano, Italy) - at a flow rate of $2.0 \mathrm{~mL} / \mathrm{min}$ using a mixture of $\mathrm{MeOH}-\mathrm{H}_{2} \mathrm{O}$ as the eluent.

\subsection{Materials}

The propolis samples were provided during 2016 by Società Agricola Artemide snc (Pietradefusi, Avellino, Campania, Italy). The samples were collected in four different rural areas located in the Avellino (AV) and Benevento (BN) provinces (Pietradefusi (AV), Melito Irpino (AV), Melizzano (BN), Vallata (AV)). The pomegranates and Aglianico grape pomace (residue from the first grape processing, formed from stalks, peels, and grape seeds) were collected in the rural area of Ariano Irpino (AV). All the samples were frozen, ground, and homogenized prior to beginnning the extraction procedures.

\subsection{Extraction}

\subsubsection{Preliminary Laboratory Scale Investigation on Propolis Samples}

The comparison of four different propolis samples was carried out using $5 \mathrm{~g}$ in each of the extraction procedures. The extraction solvent was $70 \%$ ethanol in all cases. The extraction was performed with a $320 \mathrm{~W}$ Ultrasonic bath (Branson 2510E-MTH, Bransonic ${ }^{\circledR}$, Milano, Italy). The amount of solvent used was 10:1 (v/w). The sample was placed in an Erlenmayer flask with the corresponding amount of solvent and was treated with ultrasound at $25^{\circ} \mathrm{C}$ for $30 \mathrm{~min}$. Each extract was evaporated in vacuo to dryness and lyophilized until at a constant weight. The total amounts of the obtained extracts were 2.15, 2.20, 2.25, and $2.32 \mathrm{~g}$ for Pietradefusi, Melito Irpino, Melizzano, and Vallata, respectively.

\subsubsection{Scale up Extract Preparation}

The three natural products, Pietradefusi propolis (400 g), pomegranate peel (400 g), and Aglianico grape pomace $(5 \mathrm{~kg})$, used in the biological study were obtained at BioGem (Ariano Irpino) using the Naviglio ${ }^{\circledR}$ extractor (EXNA0020, Napoli, Italy); Milli-Q water was used as solvent for the extraction of grape pomace, while propolis and pomegranate peel were extracted with $70 \%$ ethanol solution. The Naviglio ${ }^{\circledR}$ extraction was carried out by subjecting the sample to a total of 30 programmed cycles of pressure (with a maximum pressure of 10 bars), applied to the liquid phase in contact with the propolis over a period of $3 \mathrm{~h}$. The amount of solvent used was 5:1 (v/w). The number of hits in the dynamic phase (nd) was 12; the dynamic operative phase (td) and the static operative phase (ts) were performed for 2 min each. The extracts obtained were freeze-dried using a Stellar Millrock ST8S5-1 lyophilizer (Terni, Italy) to obtain $100 \mathrm{~g}$ of propolis, $50 \mathrm{~g}$ of pomegranate peel, and $250 \mathrm{~g}$ of grape pomace extracts. The pietradefusi propolis extract obtained by using the Naviglio ${ }^{\circledR}$ extractor (Napoli, Italy) was compared to that prepared with ultrasonic extraction by LC-MS analyses (see Section 3.4), obtaining an identical chemical profile (data not shown). 


\subsection{LC-MS Analyses}

\subsubsection{Quali-Quantitative Analyses of Phenols in Propolis Extracts}

All the propolis extracts were dissolved in $\mathrm{MeOH}$ at a final concentration of $2.0 \mathrm{mg} / \mathrm{mL}$, then centrifuged for $10 \mathrm{~min}$ at $1145 \times \mathrm{g}$. The supernatants $(20 \mu \mathrm{L}$ injection volume) were subjected to chemical analyses by a HPLC-PDA/UV-ESI-MS/MS system composed of a Surveyor autosampler, a Surveyor LC pump, a Surveyor PDA/UV detector, and an LCQ Advantage ESI-ion trap mass spectrometer (ThermoFinnigan, San Jose, CA, USA) equipped with Xcalibur 3.1 software. A Luna (C-18) column, $4.6 \times 150 \mathrm{~mm}, 5 \mu \mathrm{m}$ (Phenomenex, Bologna, Italy) was used for LC-MS analyses, eluting with a mixture of acetonitrile (solvent $\mathrm{A}$ ) and formic acid in water $0.1 \% v / v$ (solvent $\mathrm{B}$ ) and using the following solvent gradient in the ESI negative ion mode: $0-5 \mathrm{~min}, 5-10 \% \mathrm{~A} ; 5-10 \mathrm{~min}, 10-15 \% \mathrm{~A}$; 10-15 min, $15-20 \%$ A; $15-20$ min, 20-25\% A; 20-40 min, 25-30\% A; 40-45 min, 30-35\% A; 45-55 min, $35-40 \% \mathrm{~A} ; 55-65 \mathrm{~min}, 40-60 \% \mathrm{~A} ; 65-75 \mathrm{~min}, 60-90 \% \mathrm{~A}$. In the positive ion mode, the following solvent gradient was used: $0-5 \mathrm{~min}, 5-10 \%$ A; $5-10 \mathrm{~min}, 10-15 \%$ A; $10-15 \mathrm{~min}, 15-20 \% \mathrm{~A} ; 15-20 \mathrm{~min}, 20-25 \%$ A; 20-40 min, 25-30\% A; 40-45 min, 30-35\% A; 45-55 min, 35-40\% A; 55-65 min, 40-60\% A; 65-75 min, $60-75 \% \mathrm{~A}$. Analyses were performed at a flow rate of $0.8 \mathrm{~mL} / \mathrm{min}$, with a splitting system of 2:8 to the MS detector $(160 \mu \mathrm{L} / \mathrm{min})$ and PDA detector $(640 \mu \mathrm{L} / \mathrm{min})$, respectively. PDA/UV data were recorded at $200-600 \mathrm{~nm}$ using 254,280 , and $325 \mathrm{~nm}$ as preferential channels. The ESI interface was used both in the negative and positive ion modes, with a scan range of $m / z 150-2000$, using $\mathrm{N}_{2}$ as a sheath and auxiliary gas. The ionization conditions used in the negative ion mode were previously reported [41], while in the positive ion mode they were optimized as follows: capillary temperature, $250{ }^{\circ} \mathrm{C}$; source voltage, $4.50 \mathrm{kV}$; capillary voltage, $29.0 \mathrm{~V}$; tube lens offset, $50 \mathrm{~V}$; sheath gas flow rate, 60.00 arbitrary units; auxiliary gas flow rate, 3.00 arbitrary units. The ESI-MS/MS experiments were performed using $35.0 \%$ normalized collision energy.

Quantitative analyses of the main phenolics detected in all the analysed propolis extracts were performed by different calibration curves using the following standards: (a) positive ion mode: quercetin (concentration range $0.007-1.0 \mathrm{mg} / \mathrm{mL}$ ), luteolin (concentration range $0.003-0.500 \mathrm{mg} / \mathrm{mL}$ ), pinobanksin 5-methyl ether (concentration range $0.003-0.500 \mathrm{mg} / \mathrm{mL}$ ), and alpinetin (concentration range $0.001-0.500 \mathrm{mg} / \mathrm{mL}$ ), to quantify flavonols, flavones, dihydroflavonols, and flavanone, respectively; (b) negative ion mode: caffeic acid prenyl ester (concentration range $0.0025-1.0 \mathrm{mg} / \mathrm{mL}$ ) and pinobanksin 3-O-acetate (concentration range $0.003-0.5 \mathrm{mg} / \mathrm{mL}$ ) to quantify caffeic acid and pinobanksin derivates, respectively. The stock solutions $(1 \mathrm{mg} / \mathrm{mL})$ were prepared for each standard and at least four different concentrations obtained by serial dilution were injected in triplicate. Each calibration curve was generated by using concentration $(\mathrm{mg} / \mathrm{mL})$ with respect to the area obtained from the integration of the MS molecular ion of each standard $\left([\mathrm{M}-\mathrm{H}]^{-}\right.$in the negative ion mode and $[\mathrm{M}+\mathrm{H}]^{+}$in the positive mode). The relation between the variables was analyzed using linear simple correlation. All the propolis extracts were injected in triplicate and the amount of each constituent of propolis extract was calculated by using a GraphPad Software Prism 6.0 and finally expressed as $\mathrm{g} / 100 \mathrm{~g}$ of raw propolis.

\subsubsection{Chemical Characterization of Pomegranate Peel and Grape Pomace}

The pomegranate extract was dissolved in $\mathrm{MeOH}(2.5 \mathrm{mg} / \mathrm{mL})$, centrifuged for $10 \mathrm{~min}$ at $1145 \times g$ and injected into the HPLC-PDA/UV-ESI-MS/MS (20 $\mu \mathrm{L}$ injection volume). A Synergi Fusion-RP column, $4.6 \times 150 \mathrm{~mm}, 4 \mu \mathrm{m}$ particle size (Phenomenex, Bologna, Italy) was used, eluting at a flow rate of $0.8 \mathrm{~mL} / \mathrm{min}$ with methanol (solvent $\mathrm{A}$ ) and formic acid in water $0.1 \% v / v$ (solvent $\mathrm{B}$ ), developing a linear gradient of increasing 5\% to 55\% A within $50 \mathrm{~min}$. The ESI interface was used in the negative ion mode (scan range of $m / z$ 150-2000) with the same ionization conditions utilized for the propolis extract analyses. The PDA/UV data were registered in a wavelength range of 200-600 nm, using 254, 280 , and $325 \mathrm{~nm}$ as preferential channels. 
The grape pomace was dissolved in formic acid in water $0.1 \% v / v$ and analyzed by a LTQ-Orbitrap XL mass spectrometer (Thermo Fisher Scientific Inc., Bremen, Germany). The elution was performed on a Luna C-18 column $100 \times 2 \mathrm{~mm}, 2.5 \mu \mathrm{m}$ (Phenomenex, Bologna, Italy) at a flow rate of $0.2 \mathrm{~mL} / \mathrm{min}$ (10 $\mu \mathrm{L}$ injection volume), using a mixture of formic acid in water $0.1 \% v / v$ (solvent $\mathrm{A}$ ) and acetonitrile (solvent B) and had the following linear solvent gradient: 5\% to 95\% of B in $40 \mathrm{~min}$. The ESI interface was used in the positive ion mode (scan range of $m / z$ 200-1000), using $\mathrm{N}_{2}$ as a sheath and auxiliary gas. The ionization conditions were optimized as follows: capillary temperature, $275^{\circ} \mathrm{C}$; source voltage, $5.0 \mathrm{kV}$; capillary voltage, $35.0 \mathrm{~V}$; tube lens offset, $100 \mathrm{~V}$; sheath gas flow rate, 30.00 arbitrary units; auxiliary gas flow rate, 10.00 arbitrary units. The ESI-MS/MS experiments were performed using a $30.0 \%$ normalized collision energy.

\subsection{Collagen-Induced Arthritis Assay}

The 8-12-weeks-old female DBA/1j mice were purchased from Charles River Laboratories. The mice were housed inside individually ventilated cages (IVC) of polisulfone, keeping the temperature and humidity constant. All the animal studies were conducted in accordance with ethics approval obtained from the Italian Ministry of Health (D.Lgs. 26/2014), and all the experiments were in accordance with the European guidelines for the care and use of laboratory animals (Directive 2010/63/EU). Food and drinking water were supplied ad libitum. Each mouse was offered daily a complete pellet diet (GLP 4RF21, Mucedola s.r.l, Milano, Italy) throughout the study. The CIA was elicited by immunization with collagen CII (C9301-5MG, Sigma Aldrich, Milano, Italy) emulsified in Complete Freund's Adjuvant (CFA, F5881-10ML, Sigma Aldrich, Milano, Italy) and Incomplete Freund's Adjuvant (IFA, F5506-10ML, Sigma Aldrich, Milano, Italy) by intradermal injections ( $50 \mu \mathrm{L} / \mathrm{mouse})$. The emulsion was prepared with equal volumes of CII and CFA or IFA, considering $50 \mu \mathrm{L}$ of emulsion per mouse. For immunization, an intradermal injection was made at about $1.5 \mathrm{~cm}$ distal from the base of the tail. An amount of $50 \mu \mathrm{L}$ of CII+CFA (day 1) or CII+IFA (day 29, booster injection) emulsion was slowly injected.

The DBA/1J mice were divided into four experimental groups (5 mice/group): Group 1, non-induced control group, treated with vehicle (5\% TWEEN ${ }^{\circledR} 80$ in $\left.\mathrm{H}_{2} \mathrm{O}, 10 \mathrm{~mL} / \mathrm{kg}\right)$; Group 2, CIA-induced positive control group (treated with $50 \mu \mathrm{L}$ of bovine type II collagen emulsified in CFA on day +1 and +21); Group 3, collagen-induced mice treated with the PPP mixture (propolis $(100 \mathrm{mg} / \mathrm{kg})+$ pomegranate extract $(25 \mathrm{mg} / \mathrm{kg})+$ pomace extract $(25 \mathrm{mg} / \mathrm{kg}))$, dissolved in vehicle, from the day +1 ; Group 4 , treated with the PPP mixture from day +22 . The water or mixture was orally administered by gavage.

The evaluation of the onset of the disease was evaluated weekly by observing the characteristic symptoms of the disease on the animals' paws and assigning a degree of severity (score) as described previously and reported in Table 6.

Table 6. Scoring system for the subjective evaluation of arthritis severity.

\begin{tabular}{cc}
\hline Severity Score & Degree of Inflammation \\
\hline 0 & No evidence of erythema and swelling \\
1 & Erythema and mild swelling confined to the tarsals or ankle joint \\
3 & Erythema and mild swelling extending from the ankle to the tarsals \\
4 & Erythema and moderate swelling extending from the ankle to metatarsal joints \\
& Erythema and severe swelling encompass the ankle, foot and digits, or ankylosis of \\
the limb
\end{tabular}

At the end of the study period (36 days), the score was calculated for each paw of each animal (5 group animals/20 paws per group), and a qualitative assessment of the associated inflammatory state was also performed using Pulsed Wave (PW) doppler echography (Figure 5). 


\section{SCORE 0}

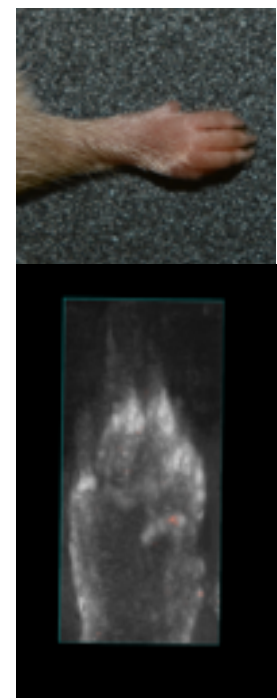

SCORE 1

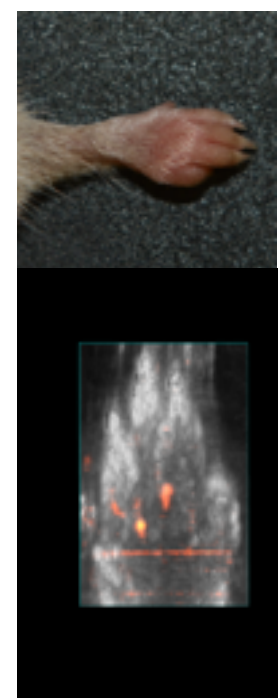

SCORE 2

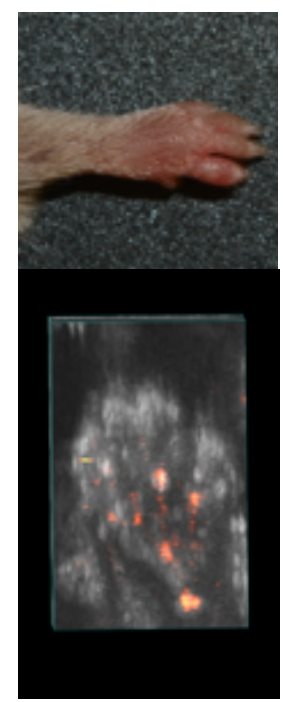

SCORE 3

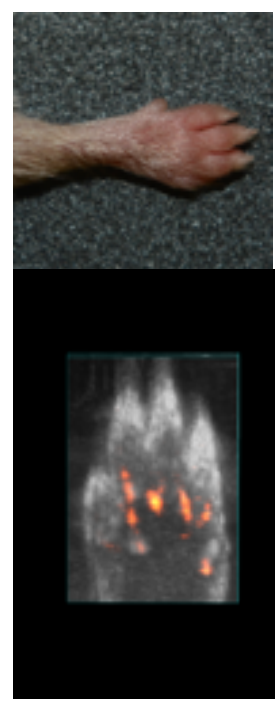

SCORE 4

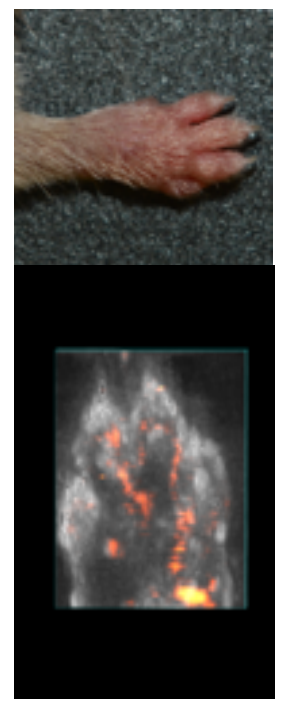

Figure 5. Arthritic paws with severity scores and associated Pulsed Wave (PW) inflammatory status.

Serum was collected from untreated and treated animals at different days +36 and kept frozen at $-20{ }^{\circ} \mathrm{C}$ until analysis. A commercially available ELISA kit was performed according to the manufacturer's instructions for the analysis of IL-17 (E-EL-M0047), IL-1b (E-ELM0037), and IL-6 (E-EL-M0044) (Elabscience, Verona, Italy). The cytokine concentration has been determined by interpolation with the 4-PL standard curve, using the GraphPad Prism v7 software (GraphPad, Arezzo, Italia).

\subsection{Statistical Analysis}

Statistical analyses have been performed by GraphPad Prism v7 software (GraphPad, Arezzo, Italia). The ELISA data are expressed as mean (SEM). A Kruskal-Wallis test followed by Dunn's post test was used for the statistical analyses of multiple comparisons.

\section{Conclusions}

Our study highlights the impact of the PPP mixture on RA onset and progression. By using in vivo CIA mouse model, we confirmed that treatment with PPP alleviated the severity of clinical symptoms. Furthermore, an early PPP treatment was associated with a reduction in the serum levels of IL-17 and IL-17-triggering cytokines. Therefore, it is plausible that PPP treatment, by preventing the IL-17 and IL-1b increase, could improve/expand the current therapeutic options for RA patients.

Moreover, our results confirmed the anti-inflammatory activity of a traditional rural preparation from internal Campanian areas based on propolis and grape pomace. The high polyphenols content of the PPP herbal preparation is strictly linked to its anti-inflammatory activity and could be considered as a starting material to develop a new valuable herbal preparation against RA. Currently, the pharmacological approaches to treat RA patients use non-steroidal, anti-inflammatory, or disease-modifying antirheumatic drugs. The side effects of these drugs can be overcome by the identification of natural products capable of relieving the symptoms of RA.

Author Contributions: Conceptualization, C.P. and N.D.T.; data curation, A.F.; methodology, A.F.; validation, E.L.D., M.D.L.; formal analysis, A.V. and M.D.L.; investigation, V.P., G.S., M.S., F.C. (Francesco Cardile), and F.C. (Fabiana Colelli); resources, N.D.T.; writing-original draft preparation, A.B. and C.P.; writing-review and editing, N.D.T.; visualization, V.P.; supervision, A.B. and C.P.; funding acquisition, N.D.T. All authors have read and agreed to the published version of the manuscript.

Funding: This work was financially supported by FARB 2018, University of Salerno. 
Acknowledgments: The authors wish to thank Società Agricola Artemide snc (Pietradefusi, Avellino, Campania, Italy) for providing the propolis samples.

Conflicts of Interest: The authors declare no conflict of interest.

\section{References}

1. van der Woude, D.; van der Helm-van Mil, A.H.M. Update on the epidemiology, risk factors, and disease outcomes of rheumatoid arthritis. Best Pract. Res. Clin. Rheumatol. 2018, 32, 174-187. [CrossRef]

2. Smolen, J.S.; Aletaha, D.; McInnes, I.B. Rheumatoid arthritis. Lancet 2017, 388, 2023-2038. [CrossRef]

3. Carmona, L.; Cross, M.; Williams, B.; Lassere, M.; March, L. Rheumatoid arthritis. Best Pract. Res. Clin. Rheumatol. 2010, 24, 733-745. [CrossRef] [PubMed]

4. Spel, L.; Martinon, F. Inflammasomes contributing to inflammation in arthritis. Immunol. Rev. 2020, 294, 48-62. [CrossRef] [PubMed]

5. Khan, M.A.; Khurana, N.; Ahmed, R.S.; Umar, S.; Md, G.; Sarwar, A.H.; Alam, Q.; Kamal, M.A.; Ashraf, G.M. Chemokines: A potential therapeutic target to suppress autoimmune arthritis. Curr. Pharm. Des. 2019, 25, 2937-2946. [CrossRef]

6. Kishore, N.; Kumar, P.; Shanker, K.; Verma, A.K. Human disorders associated with inflammation and the evolving role of natural products to overcome. Eur. J. Med. Chem. 2019, 179, 272-309. [CrossRef]

7. Attiq, A.; Jalil, J.; Husain, K.; Ahmad, W. Raging the war against inflammation with natural products. Front. Pharmacol. 2018, 9, 976. [CrossRef]

8. Fonseca, L.J.S.; Nunes-Souza, V.; Goulart, M.O.F.; Rabelo, L.A. Oxidative stress in rheumatoid arthritis: What the future might hold regarding novel biomarkers and add-on therapies. Oxid. Med. Cell. Longev. 2019, 2019, 7536805. [CrossRef]

9. Dudics, S.; Langan, D.; Meka, R.R.; Venkatesha, S.H.; Berman, B.M.; Che, C.-T.; Moudgil, K.D. Natural products for the treatment of autoimmune arthritis: Their mechanisms of action, targeted delivery, and interplay with the host microbiome. Int. J. Mol. Sci. 2018, 19, 2508. [CrossRef]

10. Mphahlele, R.R.; Fawole, O.A.; Stander, M.A.; Opara, U.L. Preharvest and postharvest factors influencing bioactive compounds in pomegranate (Punica granatum L.)-A review. Sci. Hort. 2014, 178, 114-123. [CrossRef]

11. Teixeira, A.; Eiras-Dias, J.; Castellarin, S.D.; Gerós, H. Berry Phenolics of grapevine under challenging environments. Int. J. Mol. Sci. 2013, 14, 18711-18739. [CrossRef] [PubMed]

12. Brighenti, V.; Groothuis, S.F.; Prencipe, F.P.; Amir, R.; Benvenuti, S.; Pellati, F. Metabolite fingerprinting of Punica granatum L. (pomegranate) polyphenols by means of high-performance liquid chromatography with diode array and electrospray ionization-mass spectrometry detection. J. Chromatogr. A 2017, 1480, $20-31$. [CrossRef] [PubMed]

13. Fontana, A.R.; Antoniolli, A.; Bottini, R. Grape pomace as a sustainable source of bioactive compounds: Extraction, characterization, and biotechnological applications of phenolics. Agric. Food Chem. 2013, 61, 8987-9003. [CrossRef] [PubMed]

14. Ruberto, G.; Renda, A.; Daquino, C.; Amico, V.; Spatafora, C.; Tringali, C.; De Tommasi, N. Polyphenol constituents and antioxidant activity of grape pomace extracts from five Sicilian red grape cultivars. Food Chem. 2007, 100, 203-210. [CrossRef]

15. Guaita, M.; Bosso, A. Polyphenolic characterization of grape skins and seeds of four Italian red cultivars at harvest and after fermentative maceration. Foods 2019, 8, 395. [CrossRef] [PubMed]

16. Saftic, L.; Persuric, Z.; Fornal, E.; Pavlesic, T. Targeted and untargeted LC-MS polyphenolic profiling and chemometric analysis of propolis from different regions of Croatia. J. Pharm. Biomed. Anal. 2019, 165, 162-172. [CrossRef]

17. Silva-Carvalho, R.; Baltazar, F. Almeida-Aguiar. Propolis, a complex natural product with a plethora of biological activities that can be explored for drug development. Evid. Based Complement. Alternat. Med. 2015, 206439. [CrossRef]

18. Tanaka, M.; Okamoto, Y.; Fukui, T.; Masuzawa, T. Suppression of interleukin 17 production by Brazilian propolis in mice with collagen-induced arthritis. Inflammopharmacology 2012, 20, 19-26. [CrossRef]

19. Gupta, M.; Dey, S.; Marbaniang, D.; Pal, P.; Ray, S.; Mazumder, B.J. Grape seed extract: Having a potential health benefits. Food Sci. Technol. 2020, 57, 1205-1215. [CrossRef] 
20. Rodríguez-Pérez, C.; García-Villanova, B.; Guerra-Hernández, E.; Verardo, V. Grape seeds proanthocyanidins: An overview of in vivo bioactivity in animal models. Nutrients 2019, 11, 2435. [CrossRef]

21. Mossalayi, M.D.; Rambert, J.; Renouf, E.; Micouleau, M.; Mérillon, J.M. Grape polyphenols and propolis mixture inhibits inflammatory mediator release from human leukocytes and reduces clinical scores in experimental arthritis. Phytomedicine 2014, 21, 290-297. [CrossRef] [PubMed]

22. Harzallah, A.; Hammami, M.; Kępczyńska, M.A.; Hislop, D.C.; Arch, J.R.; Cawthorne, M.A.; Zaibi, M.S. Comparison of potential preventive effects of pomegranate flower, peel and seed oil on insulin resistance and inflammation in high-fat and high-sucrose diet-induced obesity mice model. Arch. Physiol. Biochem. 2016, 122, 75-87. [CrossRef] [PubMed]

23. Neyrinck, A.M.; Van Hée, V.F.; Bindels, L.B.; De Backer, F.; Cani, P.D.; Delzenne, N.M. Polyphenol-rich extract of pomegranate peel alleviates tissue inflammation and hypercholesterolaemia in high-fat diet-induced obese mice: Potential implication of the gut microbiota. Br. J. Nutr. 2013, 109, 802-809. [CrossRef] [PubMed]

24. Rasheed, Z.; Akhtar, N.; Anbazhagan, A.N.; Ramamurthy, S.; Shukla, M.; Haqqi, T.M. Polyphenol-rich pomegranate fruit extract (POMx) suppresses PMACI-induced expression of pro-inflammatory cytokines by inhibiting the activation of MAP Kinases and NF- $\mathrm{kB}$ in human KU812 cells. J. Inflamm. 2009, 6, 1. [CrossRef] [PubMed]

25. De Nisco, M.; Manfra, M.; Bolognese, A.; Sofo, A.; Scopa, A.; Tenore, G.C.; Pagano, F.; Milite, C.; Russo, M.T. Nutraceutical properties and polyphenolic profile of berry skin and wine of Vitis vinifera L. (cv. Aglianico). Food Chem. 2013, 140, 623-629. [CrossRef]

26. Falcão, S.I.; Tomása, A.; Valec, N.; Gomesc, P.; Freireb, C.; Vilas-Boasa, M. Phenolic quantification and botanical origin of Portuguese propolis. Ind. Crop. Prod. 2013, 49, 805-812. [CrossRef]

27. Pellati, F.; Prencipe, F.P.; Bertelli, D.; Benvenuti, S. An efficient chemical analysis of phenolic acids and flavonoids in raw propolis by microwave-assisted extraction combined with high-performance liquid chromatography using the fused-core technology. J. Pharm. Biomed. Anal. 2013, 81, 126-132. [CrossRef]

28. De Zordi, N.; Cortesi, A.; Kikic, I.; Moneghini, M.; Solinas, D.; Innocenti, G.; Portoland, A.; Baratto, G.; Dall'Acqua, S. The supercritical carbon dioxide extraction of polyphenols from propolis: A central composite design approach. J. Supercrit. Fluid 2014, 95, 491-498. [CrossRef]

29. Pellati, F.; Orlandini, G.; Pinetti, D.; Benvenuti, S. HPLC-DAD and HPLC-ESI-MS/MS methods for metabolite profiling of propolis extracts. J. Pharm. Biomed. Anal. 2011, 55, 934-948. [CrossRef]

30. Fischer, U.A.; Carle, R.; Kammerer, D.R. Identification and quantification of phenolic compounds from pomegranate (Punica granatum L.) peel, mesocarp, aril and differently produced juices by HPLC-DAD-ESI/MS(n). Food Chem. 2011, 127, 807-821. [CrossRef]

31. Mena, P.; Calani, L.; Dall'Asta, C.; Galaverna, G.; García-Viguera, C.; Bruni, R.; Crozier, A.; Del Rio, D. Rapid and comprehensive evaluation of (poly)phenolic compounds in pomegranate (Punica granatum L.) juice by UHPLC-MS $^{n}$. Molecules 2012, 17, 14821-14840. [CrossRef] [PubMed]

32. Asenstorfer, R.E.; Markides, A.J.; Iland, P.G.; Jones, G.P. Formation of vitisin A during red wine fermentation and maturation. Aus. J. Grape Wine Res. 2003, 9, 40-46. [CrossRef]

33. Bakker, J.; Timberlake, C.F. Isolation, identification, and characterization of new color-stable anthocyanins occurring in some red wines. J. Agric. Food Chem. 1997, 45, 35-43. [CrossRef]

34. Flamini, R. Recent applications of mass spectrometry in the study of grape and wine polyphenols. Int. Sch. Res. Notices-Spectroscopy 2013, 2013, 813563. [CrossRef]

35. Kammerer, D.; Claus, A.; Carle, R.; Schieber, A. Polyphenol screening of pomace from red and white grape varieties (Vitis vinifera L.) by HPLC-DAD-MS/MS. J. Agr. Food Chem. 2004, 52, 4360-4367. [CrossRef]

36. Jara-Palacios, M.J.; Hernanz, D.; Cifuentes-Gomez, T.; Escudero-Gilete, M.L.; Heredia, F.J.; Spencer, J.P. Assessment of white grape pomace from winemaking as source of bioactive compounds, and its antiproliferative activity. Food Chem. 2015, 183, 78-82. [CrossRef]

37. Taams, L.S. Interleukin-17 in rheumatoid arthritis: Trials and tribulations. J. Exp. Med. 2020, 217 , e20192048. [CrossRef]

38. Choi, E.M.; Kim, Y.H. A preliminary study of the effects of an extract of Ligularia fischeri leaves on type II collagen-induced arthritis in DBA/1J mice. Food Chem. Toxicol. 2008, 46, 375-379. [CrossRef]

39. Lee, J.H.; Lim, H.; Kwon, Y.S.; Kim, H.P. New phytoformula (CAS) containing the roots of Cyathula officinalis, Achyranthes japonica and Sophora subprostrata inhibits collagen-induced arthritis in mice. Nat. Prod. Sci. 2014, $20,17-21$. 
40. Nho, J.-H.; Lee, H.-J.; Jung, H.-J.; Jang, J.-H.; Lee, K.-H.; Kim, A.-H.; Sung, T.-K.; Cho, H.-W. Effect of Saururus chinensis leaves extract on type II collagen-induced arthritis mouse model. BMC Complement. Altern. Med. 2019, 19, 2. [CrossRef]

41. Da Pozzo, E.; De Leo, M.; Faraone, I.; Milella, L.; Cavallini, C.; Piragine, E.; Testai, L.; Calderone, V.; Pistelli, L.; Braca, A.; et al. Antioxidant and antisenescence effects of bergamot juice. Oxidative Med. Cell. Longev. 2018, 9395804. [CrossRef] [PubMed]

Sample Availability: Samples of the compounds alpinetin, caffeic acid prenyl ester, luteolin, pinobanksin 5-methyl ether, and pinobanksin 3-O-acetate are available from the authors.

(C) 2020 by the authors. Licensee MDPI, Basel, Switzerland. This article is an open access article distributed under the terms and conditions of the Creative Commons Attribution (CC BY) license (http://creativecommons.org/licenses/by/4.0/). 